\title{
Bringing Blockchain Technology to Construction Engineering Management
}

\author{
Apichart Boonpheng ${ }^{1}$ \\ ${ }^{* 1}$ A Ph.D Student in the Engineering Law and Inspection \\ Program, Ramkhamheng University; \\ Asst. Prof. Dr. Waranon Kongsong ${ }^{2}$ \\ ${ }^{* 2}$ Assistant Professor in the Engineering Law and \\ Inspection \\ Faculty of Engineering, Ramkhamhaeng University;
}

\author{
Dr. Nopagon Usahanunth ${ }^{3}$ \\ ${ }^{*} 3$ Lecturer in Faculty of Public Health, \\ Western University \\ Kanchanaburi Campus; \\ Dr. Chaiwat Pooworakulchai ${ }^{4}$ \\ ${ }^{* 4}$ Lecturer in the Engineering Law and Inspection \\ Program, \\ Faculty of Engineering, Ramkhamhaeng University;
}

\begin{abstract}
The objectives of this research are to study the feasibility and application of blockchain technology in the management of construction engineering, which using qualitative research methods. From in-depth interviews with experts who work in the construction management industry and blockchain technology. The study found that, the bringing Blockchain technology in the management of construction engineering is possible, consisting of 5 areas: cost, time, quality, transparency, and information security. The apply Blockchain technology to reduce costs or limit the cost of centralized data auditing, including security and transparency. That it can use in the management of construction engineering since beginning the project through the process on the way to the project delivery.
\end{abstract}

Keywords- Blockchain technology; Engineering management; Construction project

\section{INTRODUCTION}

The construction industry is part of the country's overall economic indicators [1] and is a long-standing industry. Currently, there has been a lot of development. For the work of the construction project management, it is necessary to use knowledge in a variety of disciplines. Usually, the goals of the project are defined as 3 main components which are cost, time, quality [2] to make the construction successful and efficiently. Especially, the applied technological innovations are for the management of construction engineering.

The implementation of the Blockchain was initiated using financial technology (FinTech) and is now extended to other industries. [3] Blockchain technology is a technology that is free of data centers, which is a distributed database that contains sharing and agreement in the peer-to-peer network [4] distributed membership It consists of a linked sequence of secure time-blocking transactions from public key encryption and validated by the network community. There is no need for a reliable intermediary. [5] Therefore, the system that brought this technology Use with transparency and high security. Information is current. Can check whether data at a particular time is reasonable or not. [6] Therefore, blockchain is a decentralized and decentralized data structure for storing and retrieving information, which helps to ensure that data cannot be modified at any time. [7]
Construction engineering management is very necessary. Applying digital technology in administration this is because each construction project has large and diverse data, most of which are in the form of contract documents. Blockchain technology is a technology that can be applied. Construction Engineering Management for transparency and safety are with inspection documentary management from digital signatures and much more. The system will work connected via the internet [8] with those involved in the construction project. And those in the blockchain system of the construction project will know the changes in the data format, digital contract documents.

From the above it can be seen that blockchain technology is System built in transactions "Reliable" [9] when used with construction engineering management at the start of the construction project, it will reduce errors in the details of the document. That may create conflicts in work and affect many construction projects. Such as the cost of time quality In terms of transparency and on the safety side of data from the form of digital contracts resulting in the construction engineering management to see that the ability of the blockchain reliable basis for data storage at all stages of the construction project cycle although using Building Information Modeling (BIM), which is considered a centralized building data model. [10]

Therefore, the construction engineering management for construction projects when combined with blockchain technology and management, it is able to reduce data validation problems. Which will affect the project from the beginning of the project to the project delivery; Therefore, make the administration correct smoothness and agility of those involved in the project?

Blockchain plays a role for collecting information concerning who, what, and when, and is the basis for possible legal arguments. [10] "The potential of using Blockchain technology to develop in today's construction industry Therefore is an examination by technology by oneself things company construction must take into account the use of Blockchain, namely documents related to contract certification. To reduce the time to check the accuracy of the construction contract documents payments and contract documents that have been updated and proven to be transparent." [11] 
In recent years, the term "Blockchain" will be heard and often used to be used in the future. As a modern distribution technology which is generally familiar with the Blockchain, is a system operating in digital currencies such as Bitcoin, but with the characteristics of the blockchain has the ability to verify transparency and be safe Blockchain technology. It can be applied in industries such as IBM and SAMSUNG. The announcing that will try a Blockchain-based Ethereum to enhance the effectiveness of Internet of Thing (IoT) solutions. [9] With improved security features and reliability the strong Blockchain has proven to be capable enough to solve common business problems. [12] Adopting blockchain technology used in the management of construction engineering as follows.

\subsection{Applying Blockchain Technology to Construction Engineering Management in Cost.}

Blockchain technology could reduce the cost of financial infrastructure by about $\$ 15$ billion by 2022. [13] Construction engineering management is generally operating company or being a manufacturer of construction projects, there will be many costs which affect the project management Such as the use of technology for administration Blockchain technology is a new technology. There are innovations that are outstanding due to the nature of the transaction cost reduction [14] that can be used to control internal financial transactions [15] in construction projects. Providing credibility and trust can solve problems with technological methods in place of different systems, which may help reduce project delivery costs and risk by a percentage. [16] Taehyun Ko, Jaeram Lee and Doojin Ryu, said that blockchain technology Will effectively reduce the cost of inspection of the manufacturer and prevent distortion of product quality, real-time transparency In which, in terms of engineering management costs [17] and the construction sector has disputes related to payments, technology transfers, equipment rentals, and home sales. [11] With such a blockchain, it can save time and money. Significantly, if the whole process is automated and neutral, Zakaria Dakhli, Zoubeir Lafhaj and Alan Mossman concluded that using the blockchain can save $8.3 \%$ of the total cost of the construction of a residential building [18] in the form of transactions, inspections, and management of construction project.

Since Blockchain technology does not require an intermediary to verify the data, but rather as a P2P audit, there is no need for centralized audit costs or outsourcing. In the construction sector there are disputes related to payment transfers. Equipment rental and home sales with this technology, you can save significant costs if the entire process is automated and neutral. [11]

\subsection{Applying Blockchain Technology to Managing Construction Engineering in Time.}

When using Blockchain technology in engineering management will reduce the time-consuming operation due to centralized inspection procedures and able to verify and track immediately reducing time, reducing barriers to entry in many sectors [18] related to document certification in order to reduce the time required for document validation [11], therefore blockchain technology helps in auditing. Data sheets in every issue of the construction project and stored in the ledger account to make known the source of raw materials in which time matters are involved, namely document validation
Project progress tracking and document certification of the project.

Therefore, in the capacity of blockchain technology that is data collection through the management of data sets Seamless pattern distribution data each other in order to share information with everyone involved in the construction project. Therefore, reducing the time for data validation because it is an inspection by automation technology of the manual process steps and the decentralization characteristics of the system can be an advantage [19].

\subsection{Applying Blockchain Technology to Construction Engineering Management in Quality.}

In the construction engineering management, BIM is currently a new technology developed for the construction industry. That can cover from the building design to the construction quality issues from oversight and on-site inspections, work tracking, and project requirements inspections, or more quality checklists, can be recorded within the BIM. [20] But still a technology that must have a central system but the blockchain technology will have quality control checks [15] in the distributed system of those involved in the network once new information has been added to the blockchain system, it must be changed. Blockchain is able to be inspected quickly, resulting in an increase in quality for efficiency. In terms of identification change in information relating to contracts for construction engineering when using blockchain technology in construction engineering projects, efficiency will be achieved from the quality of the project in construction activities the raw materials in different aspects of the construction project and on the construction project tracking.

\subsection{Applying Blockchain Technology to Construction Engineering Management in Terms of Transparency.}

Economists say that blockchain is a reliable tool. [9] Transparency is able to help understand the consequences of decisions. [15] Use blockchain technology as a true source of information that is able to make information that is Able to do data or transactions of many people involved in engineering, construction projects in the blockchain network and no one is able to change the original information in the blockchain system. Changing unauthorized information is a fraud. [21] Because the Blockchain can be set to block the privacy of the blockchain (Privacy) by identifying the encryption of the key to ensure authenticity. Which is confidential for information and can be trusted therefore transparent cannot be changed [15]. Always reliable and able to check backwards fully automatic and accurate the information that will enter the blockchain database must be of high quality. It has to be recorded correctly in the first place to minimize errors in order to reduce the impact of the construction project. [22] If the information stored in the Blockchain is unreliable, it will turn into a waste phrase. [18] Blockchain technology is therefore transparent for construction projects such as relations of those involved in the construction project. Disputes and litigation and the data side from the cause of the conflict, there are three factors: the person, the document, and the environment. [23]

In the past, the construction engineering management in the old way caused the problem of transparency, causing the company construction engineering must encounter distrust in operations, such as found in the relationship between the 
buyer and the buyer of the construction engineering management, the supplier's confidence level is related to the cooperative behavior something like joint planning and flexibility In managing project relationships. [11] For example, the relationships of different functional lines in the construction project give good confidence in future relationships [24] and increase the efficiency of the project. This is a trusted relationship in the construction industry, involving people from different organizations such as customers, contractors, subcontractors and suppliers. [11]

\subsection{Applying Blockchain Technology to Construction Engineering Management in Information Security.}

Blockchain is a technology for tools to record the steps and conditions necessary to conduct transactions in a distributed manner: secure. Blockchain allows the ability to continuously record business transactions. [25] Aon Risk Advisor Worldwide for the construction industry estimates that $95 \%$ of building construction data will be lost when delivered to owners, Brig, the first Blockchain Company in California, is demonstrating the ability to compile and certify construction project documents in the Blockchain ledger that parties can deliver and deliver to owners as supplier. [26] So the Blockchain technology is capable of data security storage for reliable data flow [15] of construction engineering projects, such as fixing data forgery data confidentiality and project transactions.

Real-time data collection from references inspected by everyone in the blockchain network and share the information with only the people or persons involved from the permission Therefore is a reliable process from data linking in the blockchain system to Eco system with high efficiency and high security because unable to edit data Without the consent of those involved in the Blockchain system, Blockchain has the potential to facilitate the development and improvement of logbooks' reliability, operations and construction material volumes during maintenance. Blockchain is a secure privacy storage that includes sensitive sensors. [10] Blockchain users therefore have cyber security as expected. [27] Everything is all computer operations. It also increases the security of the data by storing data in the form of Distributed Ledger or distributing the data to everyone in the network. Every member in the network therefore has all the same information. [28]

\section{OBJECTIVES}

The objectives of this research are to study the feasibility and the possibility of applying Blockchain technology in the management of construction engineering as 5 dimensions, consisting of cost, time, quality, transparency and data security.

\section{RESEARCH METHODOLOGY}

This study is a qualitative research by using qualitative research principles by collecting documents, textbooks, books, related research articles. And data from interviews with five experts, industry participants and Blockchain knowledge, then summarized by analyzing the principles of construction engineering management. And synthesize guidelines for use to summarize the possibility of applying Blockchain technology in construction engineering explanation with content description it indicates that Blockchain technology can be used to manage construction engineering well and safely.

\section{RESULTS}

The study of use of Blockchain technology in construction engineering management by analyzing from the interview, indepth data from 5 experts to analyze and synthesize as in Table 1 and summarize the results.

Therefore, the use of Blockchain technology in construction engineering management when comparing the results in each side for the purposes of construction engineering management, as shown in table 1 showing the amount of blockchain technology used in construction engineering management in Thailand. Analysis results in the following.

\subsection{Applying Blockchain Technology for Construction Engineering Management in Cost.}

4.1.1 Construction project transactions. Blockchain will come to revolutionize the financial world, reduced fees for transactions of construction projects Blockchain technology regarded as digital technology is one of the main driving Force for cost reduction such as material cost, labor cost, equipment, machine.

4.1.2 Inspection of construction projects. Blockchain's systems are in a distributed fashion and are automatically checked. Systematically, without the need to hire personnel to inspect, resulting in reduced personnel costs.

4.1.3 Construction Project Management. Blockchain improves management because there is no need for an intermediary to perform various audits; it is an examination by the blockchain network itself, resulting of reducing the number of personnel.

\subsection{Applying Blockchain Technology in Construction Engineering Management in Time.}

4.2.1 Document validation. Due to basic information before beginning the construction project must be examined correctly, in an orderly manner and the Blockchain will automatically check Resulting in reduced inspection time.

4.2.2 Monitoring of project progress. Blockchain is able to track progress from various data entry processes, allowing relevant parties to inspect the project. But construction projects require personnel to closely monitor the site.

4.2.3 Document certification of the project. In the past, legalization of documents requires personnel to inspect and send to relevant parties to certify documents. But Blockchain is able to automatically check, making it faster for document certification it may occur in the process of the project. And problems in the judicial process when there are conflicts that still lack the law to support in order to be used as evidence.

\subsection{Applying Blockchain Technology to Construction Engineering Management in Terms of Quality.}

4.3.1 Construction activities. Since the activity in construction engineering requires the skills of skilled technicians and supervisor inspections to be different, although the information is from the beginning of the blockchain project, check the time, check the costs. But activities during construction are individual skills. 
4.3.2 Raw materials for different construction projects Blockchain is able to control the quality of raw materials. This is in accordance with the agreement when posting the

\section{TABLE I. SHOWS THE AMOUNT OF BLOCKCHAIN TECHNOLOGY USED IN THE MANAGEMENT OF CONSTRUCTION ENGINEERING IN} THAILAND.

\begin{tabular}{|c|c|c|c|c|c|}
\hline \multirow{2}{*}{$\begin{array}{l}\text { Guidelines for } \\
\text { application of } \\
\text { construction } \\
\text { engineering } \\
\text { management using } \\
\text { blockchain } \\
\text { technology. }\end{array}$} & \multirow{2}{*}{$\begin{array}{c}\text { The purpose of using } \\
\text { technology. }\end{array}$} & \multirow{2}{*}{$\begin{array}{l}\text { References } \\
\text { from research } \\
\text { papers. }\end{array}$} & \multirow{2}{*}{$\begin{array}{c}\text { Expert opinions of the use of blockchain } \\
\text { technology in the management of construction } \\
\text { engineering in Thailand. }\end{array}$} & \multicolumn{2}{|c|}{$\begin{array}{l}\text { Number of } \\
\text { consensus from } \\
\text { (expert) }\end{array}$} \\
\hline & & & & Agree & Disagree \\
\hline Cost & $\begin{array}{l}\text { - Transactions } \\
\text { - Inspection } \\
\text { - Management }\end{array}$ & $\begin{array}{c}{[6],[11],[13],} \\
{[14],[15],} \\
{[16][17],[18]}\end{array}$ & $\begin{array}{l}\text { Reduce the use of personnel in the examination } \\
\text { because the system will automatically check, } \\
\text { do not need to use, such as } \\
\text { 1. No need to hire a large number of employees } \\
\text { to do transactions and inspections anymore. } \\
2 \text {. Will reduce the process of inspection, } \\
\text { service and eliminate various intermediaries, } \\
\text { resulting in reduced service fees. }\end{array}$ & $\begin{array}{l}5 \\
5 \\
5\end{array}$ & $\begin{array}{l}0 \\
0 \\
0\end{array}$ \\
\hline Time & $\begin{array}{l}\text { - Check the accuracy } \\
\text { of the document. } \\
\text { - Track the progress } \\
\text { of the project } \\
\text { - Notarization }\end{array}$ & $\begin{array}{c}{[1],[11],[19],} \\
{[20]}\end{array}$ & $\begin{array}{l}\text { Basic information before starting the project } \\
\text { has no effect. And the blockchain } \\
\text { automatically checks and installs but in the } \\
\text { construction project activities, people need to } \\
\text { follow up. Therefore, document certifications } \\
\text { may be caused by operational procedures and } \\
\text { legal support. }\end{array}$ & $\begin{array}{l}5 \\
3 \\
4\end{array}$ & $\begin{array}{l}0 \\
2 \\
1\end{array}$ \\
\hline Quality & $\begin{array}{l}\text { - Construction } \\
\text { - Raw materials } \\
\text { - Monitoring of } \\
\text { project progress }\end{array}$ & $\begin{array}{c}{[1],[11],[15],} \\
{[20]}\end{array}$ & $\begin{array}{l}\text { Raw materials can be controlled, but in the } \\
\text { activities of the construction project, the skills } \\
\text { of the technician will vary according to the } \\
\text { expertise and time. }\end{array}$ & $\begin{array}{l}4 \\
5 \\
3\end{array}$ & $\begin{array}{l}1 \\
0 \\
2\end{array}$ \\
\hline Transparency & $\begin{array}{l}\text { - Relationship of } \\
\text { those involved. } \\
\text { - The occurrence of } \\
\text { disputes and lawsuits. } \\
\text { - Database }\end{array}$ & $\begin{array}{l}{[5],[6],[9]} \\
{[10],[11]} \\
{[15],[17]} \\
{[21],[22]} \\
{[23],[24]}\end{array}$ & $\begin{array}{l}\text { The examination by the information system is } \\
\text { therefore accurate and helpful in the } \\
\text { determination of conflicts before the dispute } \\
\text { but there is still no law to support the use of } \\
\text { evidence. }\end{array}$ & $\begin{array}{l}5 \\
4 \\
5\end{array}$ & $\begin{array}{l}0 \\
1 \\
0\end{array}$ \\
\hline Information security & $\begin{array}{l}\text { - Transactions due to } \\
\text { scheduling and } \\
\text { transaction } \\
\text { information. } \\
\text { - Data } \\
\text { confidentiality. } \\
\text { - Correction of data } \\
\text { forgery }\end{array}$ & $\begin{array}{c}{[6],[9],[10]} \\
{[15],[25]} \\
{[27],[28]}\end{array}$ & $\begin{array}{l}\text { Because the system has different rights } \\
\text { restrictions for people involved in different } \\
\text { projects. } \\
\text { 1. private Blockchain will give rights limited } \\
\text { to individuals and limit the number of } \\
\text { blockchain. } \\
\text { 2. Public Blockchain allows anyone in the } \\
\text { blockchain to Able to share the history of } \\
\text { digital transactions. }\end{array}$ & 4 & $\begin{array}{l}1 \\
0\end{array}$ \\
\hline
\end{tabular}

information in accordance with the requirements of the blockchain in the project. Those involved in the project will be able to check and know that it is not up to standard.

4.3.3 Monitoring of construction projects. Blockchain is able to track the operations of the construction projects of various departments of the automation project, including cost, time and quality of raw materials. But the quality of the construction project tracking also depends on the skills of personnel such as technicians or inspectors in front of the project.

\subsection{Applying Blockchain Technology to Construction} Engineering Management in Terms of Transparency.

4.4.1 Relations of those involved in the construction project. Since it is validated and verified by the information system, it is correct. But may be that still lacking confidence and personal feelings bad attitude. Therefore, to be used in conjunction with the guidelines "Moral Agreement" "Integrity Pact: IP" in accordance with the announcement of AntiCorruption Cooperation Committee on 5 July 2018 regarding guidelines and procedures for cooperating to prevent fraud in procurement. Government procurement which has set guidelines for observers (observers) who have expertise and expertise to observe in procurement from the process of drafting the scope of work to the end of the project.

4.4.2 When there are disputes and litigation. Because there is still no law to support the use of evidence because there are various events that will occur at different times of the construction project if supported by law so it will be useful in your judgment conflict before the dispute.

4.4.3 The database. Data is transparent and can be generated by validation and validation from the blockchain system, and must be legally supported by law, even if it is audited by a person related to a project on the blockchain system that is distributed accounting systems, regardless.

\subsection{Using Blockchain Technology in Construction Engineering Management in Information Security.}

4.5.1 Fixing forgery information. Blockchain has a system to limit the rights of people involved in construction projects In which the project may use a private blockchain, which is a 
closed system, built by it based on the cloud, so when it is edited it needs to be verified by people in the blockchain system and it needs to be shared.

4.5.2 Data confidentiality. The confidentiality of information is caused by the elimination of the access rights of the people involved in the construction project. But be careful, because Blockchain is a Distributed Ledger Technology (DLT) with many project-related parties. There may be interference in the inspection process. From the Blockchain gap the take over of consensus Hijack, because the Blockchain system doesn't have an intermediary.

4.5.3 Project Transactions. As the Blockchain has a system to restrict access to the database system for construction projects, it means confidentiality. The information for transactions is in the processing of secrecy and security. Therefore, the transaction of the construction project is a resolution of the persons involved in the system. Will be visible or from elimination from the Blockchain.

\section{CONCLUSION}

This research article discusses Blockchain technology innovation with the foundation of the rapidly growing Distributed Ledger Technology (DLT) for application in the engineering industry, construction projects from the above research it can be concluded that (1) Blockchain technology can be reduce costs Transactions, audits, and administration from the cost reduction of personnel for inspection and personnel channels because it is the automatic checking of Blockchain. (2) Blockchain technology can be reduce time document validation, project progress tracking, and document certification, because it is a monitoring of progress and automatic Blockchain certification but must be supported by law. (3) Blockchain technology can be managerial construction engineering for construction quality, raw materials, and monitor project progress. It can be improved because raw materials under controlled according to specifications in the activities of the construction project, there must be skilled inspectors in that activity. Therefore, the quality of the activities varies with the skills. (4) Blockchain technology is more transparent in the management of construction engineering in the relationships of those involved, the occurrence of disputes and lawsuits, and the database because the investigation was examined by the system but those involved with the project must have knowledge expertise in the project, from drafting before the beginning of the project to the end of the project. (5) Blockchain technology is data security in Transactions due to scheduling and transaction information, data confidentiality, and tampering. Because there is a restriction on the rights of people involved in the construction project and the system must only have a combination key Digital signature.

Concludes that the use of blockchain technology in the construction project engineering able to reduce costs or limit the cost of centralized data auditing, including security and transparency. From this research concluded that the advantage of Blockchain technology is possible that will use Blockchain technology for construction engineering, for example, can track contractual transaction data for inspection since starting the project through the process on the way to the project delivery. The Blockchain technology has high potential therefore more research is needed to be developed for further application in construction engineering management.

\section{REFERENCES}

[1] Pooworakulchai C, Kongsong W, and Kongbenjapuch K., (2017). "Affecting on Contract Administration in Government Construction Projects". International Journal of Applied Engineering Research ISSN 0973-4562 Volume 12, Number 9 pp. 2079-2086,

[2] Jira Damkaoeng V., (2548). Construction Management. Bangkok, Wanwee.

[3] Vincent Hargaden, Nikolaos Papakostas, Anthony Newell,Adam Khavia,and Adam Scanlon., (2019). "The Role of Blockchain Technologies in Construction Engineering Project Management". IEEE International Conference on Engineering, Technology and Innovation (ICE/ITMC)

[4] Edvard Tijan, Saša Aksentijevi'c , Katarina Ivani'c and Mladen Jardas., (2019). "Blockchain Technology Implementation in Logistics". Sustainability 2019, 11, 1185, 1 of 13, Retrieved from https://www.researchgate.net/publication/331325030_Blockchain_Tech nology_Implementation_in_Logistics.

[5] Christidis, K. and M. Devetsikiotis., (2016). "Blockchains and Smart Contracts for the Internet of Things". IEEE Access, 4, pp. 2292-2303.

[6] Sangsunt P., (2017). "Blockchain Technology: New Innovation". BUSINESS ADMINISTRATION AND ECONOMICS REVIEW, Vol 13 (2). July - December, pp. 114-130.

[7] Muhammad Muzammal, Qiang Qu and Bulat Nasrulin., (2019). "Renovating blockchain with distributed databases: An open source system". Future Generation Computer Systems 90, 105-117, Retrieved

from https://www.sciencedirect.com/science/article/pii/S0167739X18308732

[8] Ploywattanawong L, Boonkrong S., (2018). "Bitcoin \& Blockchain Technology", KKU RESEARCH JOURNAL (GRADUATE STUDY) Vol. 18 NO. 1: January-March,pp. 1-12.

[9] Beck, R., J. Stenum Czepluch, N. Lollike, and S. Malone., (2016). "Blockchain - The Gateway to Trust - free Cryptographic Transactions". 24th European Conference on Information Systems (ECIS). Istanbul, Turkey.

[10] Žiga Turka, and Robert Klinc., (2017). "Potentials of Blockchain Technology for Construction Management". Creative Construction Conference , CCC 2017. Primosten, Croatia, 2017, pp. 638-645, https://doi.org/10.1016/j.proeng.2017.08.052

[11] Jun WANG, Peng WU, Xiangyu WANG, Wenchi SHOU., (2017). "The outlook of blockchain technology for construction engineering management.”, Front. Eng. Manag. 2017, 4(1): 67-75, Retrieved from http://journal.hep.com.cn/fem/EN/10.15302/J-FEM-2017006

[12] Achal R Poonja, Ashish S K, Sagar Ramesh Pujar, Shravan Kini., (2019). "A Study on Blockchain Technology and its Applications.", International Journal of Engineering Research \& Technology (IJERT), Volume 7, Issue 08, 1-3

[13] The Fintech 2.0 Paper: rebooting financial services,. [Online]. Availablehttps://www.finextra.com/ downloads/newsdocs/the\%20fintech\%202\%200\%20paper.pdf

[14] Beck, R. and C. Müller-Bloch., (2017). "Blockchain as Radical Innovation: A Framework for Engaging with Distributed Ledgers as Incumbent Organization". 50th Hawaii International Conference on System Sciences (HICSS -51). Waikoloa, Hawaii, USA.

[15] Abeyratne S A, Monfared R P., (2016). "Blockchain ready manufacturing supply chain using distributed ledger". International Journal of Research in Engineering and Technology, 5(9): 1-10.

[16] M. Mathews, D. Robles, and B. Bowe., (2017). "BIM+Blockchain: A Solution to the Trust Problem in Collaboration?" CITA BIM Gathering 2017. Dublin, Ireland, 2017 https:// arrow.dit.ie/cgi/viewcontent.cgi?article=1032\&context=bescharcon.

[17] Taehyun Ko, Jaeram Lee and Doojin Ryu., (2018). "Blockchain Technology and Manufacturing Industry: Real-Time Transparency and Cost Savings,Sustainability", 10, 4274, Retrieved from https://www.researchgate.net/publication/329136595_Blockchain_Tech nology_and_Manufacturing_Industry_RealTime Transparency and Cost Savings

[18] Zakaria Dakhli, Zoubeir Lafhaj and Alan Mossman., (2019). "The Potential of Blockchain in Building Construction.Buildings", 9, 77, Retrieved from https://www.mdpi.com/2075-5309/9/4/77 
[19] Fridgen G,Urbach N,Radszuwill S,and Utz L., (2018). "CrossOrganizational Workflow Management Using Blockchain Technology - Towards Applicability, Auditability, and Automation". 51st Hawaii International Conference On System Sciences, (HICSS-51): 35073516, Hawaii, USA.

[20] Chong H Y, Lopez R, Wang J, Wang X, Zhao Z., (2016). "Comparative analysis on the adoption and use of BIM in road infrastructure projects". Journal of Management Engineering, 32(6): 05016021

[21] A. Mizrahi., (2015). "A Blockchain-Based Property Ownership Recording System". [Online]. Available: http://chromaway.com/papers/A-blockchainbased-property-registry.pdf

[22] Kongsong, W., (2017). The Reduction of the Impacts in the Contract Management for Government Construction Projects. International Journal of Applied Engineering Research (IJAER). 12(23), pp. 1331013313.

[23] Kongsong, W., (2017). The Factors of the Conflict in Construction Works. International Journal of Engineering Research And Management (IJERM). Volume-04, Issue-08, August 2017, 14-18. from http://www.ijerm.com
[24] Kongsong W, Pooworakulchai C., (2019). "Lawsuits in construction projects". RMUTSB Acad. J. (HUMANITIES AND SOCIAL SCIENCES), 4(1),pp. 115-121

[25] Fiander-Mccann D., (2017). "Will Blockchain transform the Construction Industry?" [J/OL] , Retrieved from https://futureofconstruction.org/blog/will-blockchain-transform-the-c onstruction-industry/.

[26] Don Tapscott and Ricardo Viana Vargas., (2019). "How Blockchain Will Change Construction" , Retrieved from https://hbr.org/2019/07/how-blockchain will-change-construction

[27] Fanning, K. and D.P. Centers., (2016). "Blockchain and Its Coming Impact on Financial Services". Journal of Corporate Accounting \& Finance, 27(5), pp. 53-57.

[28] Sawetthapong D, Kongsong W., and Srithammasak B, (2018). "The Digital Technology Law Concerning of Smart Contract in Thailand". The 2nd Conference on Innovation Engineering and Technology for Economy and Society, 16 December 2018 at Kasem Bundit University Romklao Campus 